\title{
KAJIAN EFISIENSI PERENCANAAN PC-I GIRDER DENGAN MENGGUNAKAN SISTEM STRAND 0,5" DAN 0,6" TERHADAP KEKUATAN DAN BIAYA
}

\author{
Jessen Richarlim ${ }^{1}$ dan Edison Leo ${ }^{2}$ \\ ${ }^{1}$ Program Studi Sarjana Teknik Sipil, Universitas Tarumanagara, Jl. Letjen S. Parman No.1 Jakarta \\ Jessen.325160007@stu.untar.ac.id \\ ${ }^{2}$ Program Studi Sarjana Teknik Sipil, Universitas Tarumanagara, Jl. Letjen S. Parman No.1 Jakarta \\ Edisonleo41@gmail.com
}

Masuk: 17-01-2020, revisi: 13-02-2020, diterima untuk diterbitkan: 14-02-2020

\begin{abstract}
Prestressed concrete can be defined as concrete that given internal compressive stress such that it can reduce the tensile stress caused by external load to a certain condition. Stressing applied by pulling the tendon that has been installed on the concrete. 0,5" strand system are usually used for medium span. While 0,6" strand system is used for long span bridge. The purpose of this study was to determine the efficiency of PC-I girder using 0,5 "and 0,6" strands in terms of strength and cost. Strength analysis can be calculated by stress analysis, ultimate moment analysis and deflection analysis, while for cost analysis is a comparison of the cost composition between the 0,5 "and 0,6" strand system for each structural model reviewed. Structural modeling with hinge-roll at both ends and working loadings are dead load, additional dead load and live load. Loss of prestress force that is calculated depend on SNI 1725:2016 about loading for the bridge. The analysis shows that the use of the 0,5" strand has a better cost efficiency compared to the 0,6" strand. This can be seen from the design costs of the 0,5" strand system structure model is smaller than the 0,6" strand system structure model.
\end{abstract}

Keywords: prestressed concrete; strand system; deflection; stress; ultimate moment; cost

\begin{abstract}
ABSTRAK
Beton prategang dapat didefinisikan sebagai beton yang diberikan tegangan tekan internal sedemikian rupa sehingga dapat mengurangi tegangan tarik yang terjadi akibat beban eksternal sampai suatu batas tertentu. Pemberian tegangan dilakukan dengan cara penarikan tendon yang telah diinstalasi pada beton. Sistem strand ukuran 0,5 " biasanya digunakan untuk konstruksi jembatan bentang menengah. Sedangkan sistem strand ukuran 0,6 " digunakan untuk konstruksi jembatan bentang panjang. Tujuan dari penelitian ini adalah untuk mengetahui efisiensi perencanaan PC-I girder dengan menggunakan strand 0,5" dan 0,6" dalam segi kekuatan dan biayanya. Analisis segi kekuatan berupa analisis tegangan, analisis momen ultimit dan analisis lendutan sedangkan untuk analisis segi biaya berupa perbandingan komposisi biaya yang dihasilkan dengan sistem strand 0,5" dan 0,6" untuk setiap model struktur yang ditinjau. Pemodelan struktur dengan perletakan sendi-rol pada kedua ujungnya dan pembebanan yang bekerja berupa beban mati, beban mati tambahan dan beban hidup. Kehilangan gaya prategang yang diperhitungkan sesuai dengan peraturan SNI 1725:2016 tentang Pembebanan Untuk Jembatan. Hasil analisis menunjukkan bahwa penggunaan strand 0,5 " memiliki efisiensi biaya yang lebih baik dibandingkan dengan strand 0,6 ". Hal ini dilihat dari biaya desain model struktur sistem strand 0,5 " lebih kecil dibandingkan dengan model struktur sistem strand $0,6 "$ ".
\end{abstract}

Kata kunci: beton prategang; sistem strand; lendutan; tegangan; momen ultimit; biaya

\section{PENDAHULUAN}

Jembatan merupakan suatu struktur yang memungkinkan rute transportasi melintasi sungai, danau, kali, jalan raya, jalan kereta api dan lain-lain (Manu, 1995). Fungsi lain dari jembatan yaitu memperpendek jarak tempuh dan melancarkan kegiatan berpindah sehingga waktu pelaksanaan dapat dilakukan dengan seminimal mungkin.

Akibat kemajuan teknologi tinggi di dalam ilmu bahan telah memungkinkan pelaksanaan dan perakitan sistem dengan bentang besar seperti jembatan, jembatan segmental, cerobong reaktor nuklir dan anjungan pengeboran minyak lepas pantai yang dengan mengkombinasikan beton mutu tinggi dan baja mutu tinggi secara aktif dengan 
menarik baja dan menahannya ke beton sehingga beton dalam keadaan tertekan. Karena penampang beton sebelum beban bekerja telah dalam kondisi tertekan, maka bila beban sudah bekerja, tegangan tarik yang terjadi dapat direduksi oleh tegangan tekan yang telah diberikan pada penampang sebelum bekerja. Konsep inilah yang dinamakan sebagai beton prategang (Nawy, 2001).

Pemberian tegangan pada balok prategang dilakukan pada baja prategang (tendon). Baja prategang dapat terbentuk dari kawat-kawat tunggal atau strand yang terdiri dari beberapa kawat yang dipuntir membentuk elemen tunggal dan batang-batang bermutu tinggi (Raju, 1981).

Penentuan diameter strand saat perencanaan suatu konstruksi mempertimbangkan banyak sekali faktor diantaranya faktor kekuatan dan biaya. Faktor kekuatan meliputi kemampuan struktur dalam menopang beban yang bekerja dan durabilitas struktur terhadap waktu. Faktor biaya meliputi komposisi bahan yang digunakan dalam proses konstruksi, waktu pelaksanaan dan berbagai faktor lainnya. Oleh karena itu, akan dilakukan kajian efisiensi perencanaan PC-I girder dengan membandingkan strand 0,5" dan 0,6" terhadap kekuatan dan biayanya.

Berdasarkan latar belakang masalah yang telah dijelaskan di atas, maka rumusan masalah dalam kajian ini yaitu bagaimana pengaruh kekuatan yang dihasilkan strand yang berdiameter 0,5 " dan 0,6 " pada balok prestress dan bagaimana komposisi biaya yang dihasilkan dari penggunaan strand yang berdiameter 0,5 " dan 0,6 " dalam perencanaan balok prestress?

Dari rumusan masalah diatas, maka didapat tujuan dari penulisan kajian ini untuk mengetahui pengaruh kekuatan yang dihasilkan strand yang berdiameter 0,5 " dan 0,6 " pada balok prestress dan mengetahui komposisi biaya yang dihasilkan dari penggunaan strand yang berdiameter 0,5 " dan 0,6 " dalam perencanaan balok prestress.

Studi literatur yang dilakukan dalam pengerjaan kajian ini adalah dengan membaca jurnal-jurnal yang berkaitan dengan desain jembatan prategang. Selain itu, penulis juga mempelajari dasar perhitungan dengan bantuan beberapa contoh output perhitungan perencanaan jembatan yang telah selesai dibangun. Adapun peraturanperaturan yang penulis gunakan sebagai referensi dalam kajian ini yaitu, Bridge Management System (BMS) 92, SNI 1725 - 2016 tentang Pembebanan Pada Jembatan, SNI T 12-2004 tentang Perencanaan Struktur Beton Untuk Jembatan, dan National Association Of Australian State Road Authorities (NAASRA). Studi literatur yang dilakukan juga meliputi buku-buku yang ditulis oleh para ahli, khususnya yang mengenai jembatan prategang dan beton prategang.

Beton prategang pada dasarnya adalah beton di mana tegangan-tegangan internal dengan besar serta distribusi yang sesuai diberikan sedemikian rupa sehingga tegangan-tegangan yang diakibatkan oleh beban-beban luar dilawan sampai suatu tingkat yang diinginkan.

Tiga dasar konsep untuk menganalisis sifat beton prategang (Lin, 2000) yaitu:

1. Sistem prategang untuk mengubah beton menjadi bahan elastis.

2. Sistem prategang untuk kombinasi baja mutu tinggi dengan beton mutu tinggi.

3. Sistem prategang untuk mencapai keseimbangan beban.

Dalam pemberian tegangan pada beton prategang dikenal dengan dua metode cara yang berbeda. Kedua metode tersebut membedakan sistem prategang yaitu pra-tarik (pre-tension) atau pascatarik (post-tension). Berikut penjelasan singkat tentang konsep dari setiap metode dalam pemberian gaya prategang.

1. Pratarik (Pre-Tensioning)

Pada metode pratarik, sebelum beton dicor, baja terlebih dahulu ditarik diantara dua dinding penahan dan diangkur pada ujung-ujung pelataran kerja. Kemudian beton dicor dan setelah beton mengeras, kabel-kabel diputuskan dari dinding penahan, sehingga gaya prategang mengalir pada beton.

\section{Pascatarik (Post-Tensioning)}

Pada metode pascatarik, beton terlebih dahulu dicor dengan memasukan saluran untuk menempatkan tendon. Apabila beton sudah cukup kuat, maka kawat ditarik dengan menggunakan dongkrak pada permukaan ujung batang dan kawat diangkurkan dengan pasak atau mur.

Dalam pembuatan beton prategang, dibutuhkan material-material khusus yang harus memenuhi spesifikasispesifikasi tertentu, diantaranya: 


\section{Beton}

Pada beton prategang, dibutuhkan mutu yang lebih tinggi dari kebutuhan beton bertulang pada umumnya. Beton yang digunakan dalam prategang adalah yang mempunyai kuat tekan dengan nilai f'c antara 30-45 MPa.

2. Baja

Untuk sistem beton prategang, digunakan baja yang bermutu tinggi hingga $1862 \mathrm{MPa}$ atau lebih tinggi. Baja yang bermutu tinggi akan memiliki kadar karbon yang cenderung lebih tinggi. Baja mutu tinggi diharapkan mampu menerima kekuatan tarik yang cukup tinggi untuk mampu menghasilkan gaya prategang yang cukup besar.

3. Selubung tendon $(d u c t)$

Duct merupakan salah satu material untuk prategang pascatarik yang berfungsi untuk tempat meletakkan strand.

4. Angkur (anchorages)

Angkur adalah suatu alat yang berfungsi untuk menjangkarkan tendon ke komponen struktur beton dalam sistem pascatarik atau suatu alat yang berfungsi untuk menjangkarkan tendon selama proses pengerasan beton dalam sistem pratarik.

5. Stressing Jack

Stressing jack adalah suatu alat yang berfungsi untuk memberikan tegangan pada tendon. Tegangan yang dihasilkan merupakan gaya sementara yang diakibatkan terjadinya tarikan pada beton prategang.

6. Grouting

Grouting dibutuhkan sebagai pengisi selubung baja prategang untuk metode pascatarik. Selubung terbuat dari logam dan bahan grouting adalah pasta semen.

Kehilangan gaya prategang merupakan suatu kondisi dimana berkurangnya gaya yang bekerja pada tendon akibat beberapa kondisi tertentu. Kehilangan gaya prategang dibagi menjadi 2 tipe yang akan dijelaskan sebagai berikut:

\section{Short-Term Losses}

Kondisi short-term losses adalah kehilangan gaya prategang langsung atau segera setelah beton diberi gaya prategang. Kehilangan gaya prategang disebabkan oleh perpendekan elastis beton, kehilangan akibat friksi karena perubahan kelengkungan tendon dan kehilangan akibat friksi angkur.

\section{Long-Term Losses}

Kondisi long-term losses adalah kehilangan gaya prategang yang tidak terjadi secara langsung melainkan terjadi pada kurun waktu dan besarnya kehilangan prategang merupakan besaran dari fungsi waktu. Kondisi ini disebabkan oleh rangkak dan susut pada beton serta relaksasi baja prategang.

\section{METODE PENELITIAN}

Model struktur yang dikaji dapat dilihat pada Gambar 1. Data struktur yang digunakan untuk mendesain jembatan adalah sebagai berikut :
1. Bentang jembatan
$: 30 \mathrm{~m}-35 \mathrm{~m}$
2. Tebal plat lantai jembatan
$: 25 \mathrm{~cm}$
3. Tebal deck slab
$: 7 \mathrm{~cm}$
4. Tebal aspal
$: 5 \mathrm{~cm}$
5. Tebal overlay
$: 5 \mathrm{~cm}$
6. Tebal diafragma
$: 20 \mathrm{~cm}$ 
Kajian Efisiensi Perencanaan PC-I Girder dengan Menggunakan Sistem Strand 0,5" dan 0,6" terhadap

Kekuatan dan Biaya
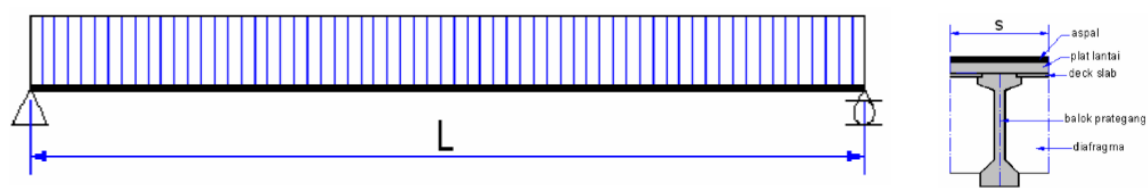

Gambar 1. Pemodelan struktur jembatan

Dimensi girder yang digunakan pada kajian ini dapat dilihat pada Gambar 2 dan Tabel 1. Spesifikasi girder dapat dilihat seperti dibawah ini:

1. Jenis girder

: PC-I Girder

2. Bentang girder

: $30-35 \mathrm{~m}$

3. Jarak antara girder (ctc)

: $1,85 \mathrm{~m}$

4. Mutu girder

: $600 \mathrm{~kg} / \mathrm{cm}^{2}$

Tabel 1 Dimensi balok prategang

\begin{tabular}{ccc}
\hline \multirow{2}{*}{ No } & \multicolumn{2}{c}{ Dimensi } \\
\cline { 2 - 3 } & $\mathrm{b}(\mathrm{mm})$ & $\mathrm{h}(\mathrm{mm})$ \\
\hline 1 & 640 & 700 \\
\hline 2 & 800 & 130 \\
\hline 3 & 300 & 120 \\
\hline 4 & 200 & 125 \\
\hline 5 & 250 & 250 \\
\hline 6 & 700 & 250 \\
\hline
\end{tabular}

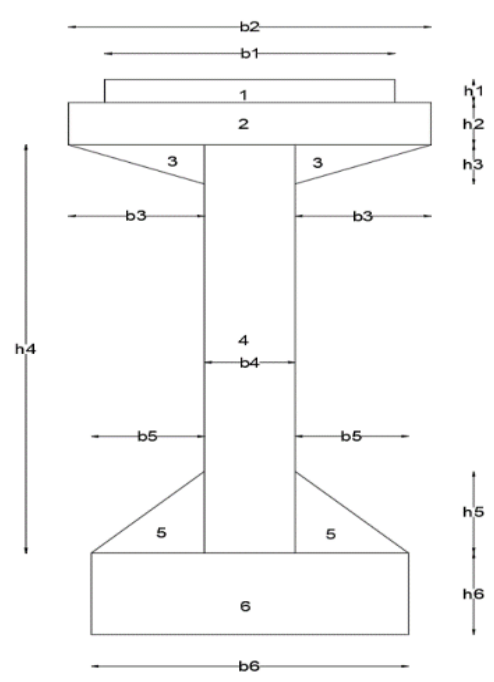

Gambar 2 Penampang balok prategang

Pembatasan suatu masalah digunakan untuk menghindari terjadinya penyimpangan atau pelebaran topik masalah. Untuk memudahkan analisis agar lebih terarah sehingga tujuan analisis tercapai, maka dilakukan pembatasan masalah pada ruang lingkup yaitu hanya dilakukan analisis pada girder beton prategang secara manual dengan bantuan program Microsoft Excel, digunakan profil girder berpenampang I, variasi bentang jembatan yang digunakan yaitu $30 \mathrm{~m}-35 \mathrm{~m}$, lebar jembatan konstan $14 \mathrm{~m}$ untuk segala variasi, sistem prategang yang digunakan adalah sistem pascatarik, diameter strand divariasikan dengan ukuran 0,5" dan 0,6", tendon prategang yang digunakan dalam perhitungan adalah jenis Strand Uncoated 7 Wire Super Strand ASTM A 416 Grade 270.

Pada tahapan kajian, data yang telah ditetapkan dan dikumpulkan akan dianalisis lebih detil untuk didapatkan hasil perencanaan yang mengacu pada peraturan Standar Nasional Indonesia. Perencanaan ini dilakukan dengan melakukan beberapa proses perhitungan. Berikut ini adalah tahapan-tahapan perhitungan yang akan dilakukan dalam kajian ini.

\section{Section Properties Girder}

Pada tahapan ini, balok prategang yang telah ditetapkan akan dianalisis pada 2 kondisi, yaitu kondisi precast dan komposit. Setiap kondisi akan dilakukan perhitungan untuk mencari nilai titik berat, inersia penampang dan section modulus.

\section{Pembebanan}

Pembebanan jembatan yang digunakan mengacu pada SNI 1725-2016 yang mengatur tentang Pembebanan Pada Jembatan. Pembebanan yang diperhitungkan dalam kajian ini hanya berdasarkan beban mati, beban mati tambahan, dan beban hidup berupa beban truck/ beban jalur. 
3. Perhitungan Momen Maksimum

Perhitungan momen maksimum dilakukan pada tengah bentang dengan prinsip kesetimbangan.

4. Menentukan Jumlah Strand

Sebelum melakukan perencanaan letak posisi tendon, banyaknya strand yang digunakan harus diperhitungkan terlebih dahulu dengan persamaan 1 dibawah ini.

$$
\mathrm{n}=\frac{\mathrm{Ft}}{\% \text { losses-transfer. fpu. Aps }} \text { atau } \frac{\mathrm{Fe}}{\% \text { losses-service. fpu. Aps }}
$$

5. Analisa Tegangan

Analisa tegangan dilakukan dengan memperhitungkan tegangan yang terjadi pada serat atas dan serat bawah saat kondisi transfer dan service. Besarnya tegangan yang terjadi pada masing-masing kondisi tidak boleh melebihi tegangan ijin yang diatur pada peraturan SNI T 12-2004 tentang Perencanaan Struktur Beton Untuk Jembatan. Berikut uraian tentang peraturan SNI T 12-2004 yang dapat dilihat pada persamaan 2 hingga 5 dibawah ini.

1. Tegangan ijin beton pada kondisi transfer:

$$
\begin{array}{ll}
\text { Tegangan tekan }(\mathrm{fci}) & =0,60 . \mathrm{f}^{\prime} \mathrm{ci}(\mathrm{MPa}) \\
\text { Tegangan tarik }(\mathrm{fti}) & =0,25 \cdot \sqrt{f^{\prime} c i}(\mathrm{MPa})
\end{array}
$$

2. Tegangan ijin beton pada kondisi service:

$$
\begin{array}{ll}
\text { Tegangan tekan }(\mathrm{fc}) & =0,45 . \mathrm{f}^{\prime} \mathrm{c}(\mathrm{MPa}) \\
\text { Tegangan tarik }(\mathrm{ft}) & =0,50 \cdot \sqrt{f^{\prime} c}(\mathrm{MPa})
\end{array}
$$

6. Analisa Lendutan

Analisa lendutan dilakukan dengan cara membandingkan lendutan yang terjadi pada kondisi transfer dan service dengan lendutan ijin sesuai peraturan SNI 12-2004 tentang Perencanaan Struktur Beton Untuk Jembatan. Pada peraturan pasal 9.2.1 batasan lendutan ijin dapat dilihat seperti pada persamaan 6 dan 7 .

$$
\begin{aligned}
\delta_{\text {total }} & <\frac{L}{300} \\
\delta_{\text {live-load }} & <\frac{L}{800}
\end{aligned}
$$

\section{Analisa Momen Ultimate}

Analisa momen ultimate dilakukan dengan membandingkan momen yang terjadi pada struktur dikalikan dengan faktor amplifikasi sesuai jenis pembebanannya terhadap kemampuan penampang struktur dalam menahan momen yang bekerja akibat pembebanan. Besarnya faktor amplifikasi digunakan sesuai peraturan SNI 1725:2016 tentang Pembebanan Jembatan. Batasan momen ultimate ijin dapat diperhitungkan sesuai dengan persamaan 8 .

$$
\mathrm{Mu}-\mathrm{Ijin}=\gamma_{\mathrm{MS}} \times \mathrm{M}_{\mathrm{MS}}+\gamma_{\mathrm{MA}} \times \mathrm{M}_{\mathrm{MA}}+\gamma_{\mathrm{LL}} \times \mathrm{M}_{\mathrm{LL}}
$$

\section{Perhitungan Komposisi Biaya Balok Prategang}

Komponen yang diperhitungkan dalam kajian ini yaitu strand, ducting, angkur, wedges dan casting. Dilakukan asumsi biaya satuan untuk memperhitungkan komposisi biaya pada balok prategang. Setelah didapat harga total dan masing-masing harga tiap komponen maka selanjutnya dapat dihitung besarnya persentase harga suatu komponen terhadap harga totalnya sehingga dapat dilihat besarnya kontribusi biaya setiap komponennya.

9. Perbandingan Model Struktur

Perbandingan model struktur dilakukan dengan membandingkan desain dengan sistem strand 0,5 " terhadap 0,6 " dalam segi biayanya. Hal ini bertujuan agar dapat dilihat fluktuasi efisiensi perbandingan biaya dengan sistem strand 0,5 " terhadap 0,6 " pada desain struktur jembatan dengan bentang $30 \mathrm{~m}-35 \mathrm{~m}$. 
Kajian Efisiensi Perencanaan PC-I Girder dengan Jessen Richarlim, et.al. Menggunakan Sistem Strand 0,5" dan 0,6" terhadap Kekuatan dan Biaya

\section{HASIL DAN PEMBAHASAN}

\section{Komposisi biaya setiap model jembatan}

Berikut disajikan komposisi biaya pada balok prestress untuk setiap model yang dikaji pada Gambar 3 hingga Gambar 8.
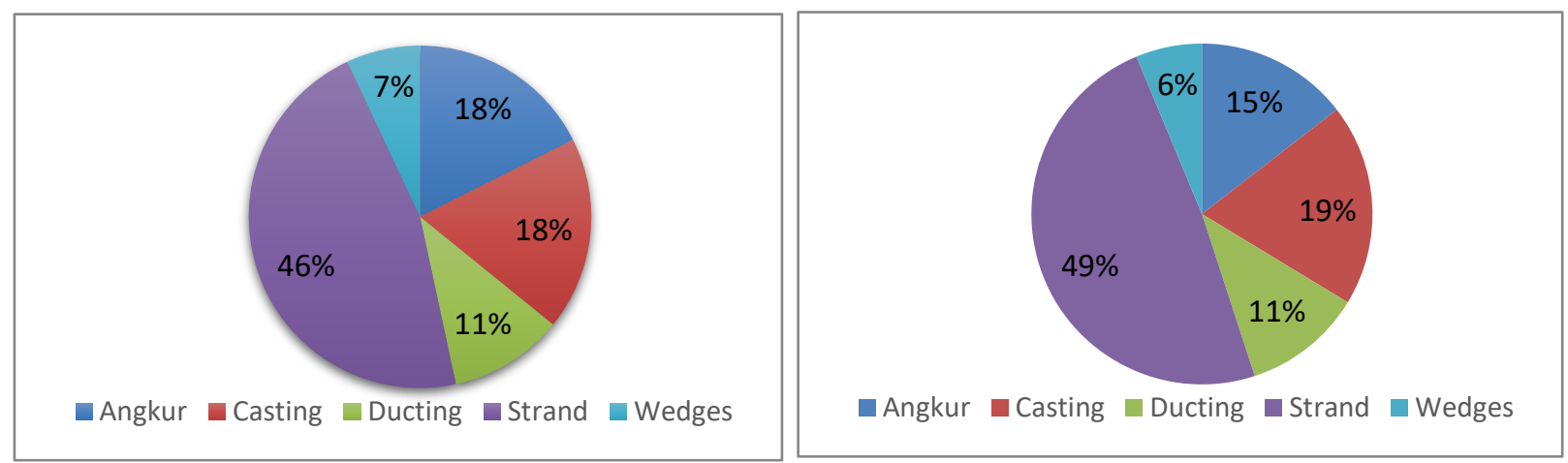

Gambar 3 Grafik komposisi biaya model jembatan bentang $30 \mathrm{~m}$ sistem strand 0,5" dan 0,6”
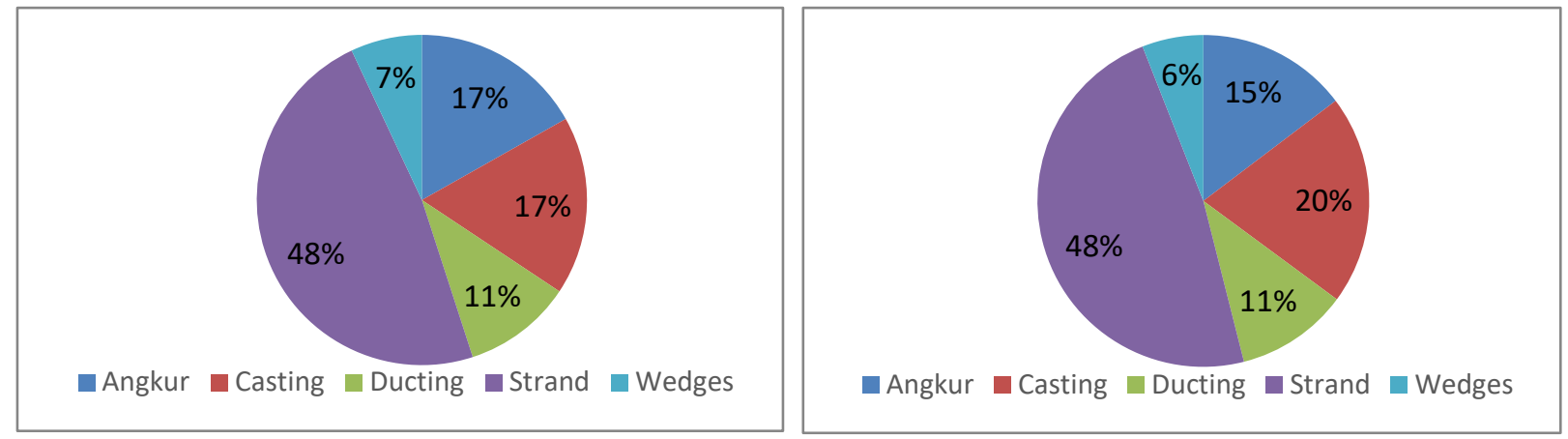

Gambar 4 Grafik komposisi biaya model jembatan bentang $31 \mathrm{~m}$ sistem strand 0,5” dan 0,6”
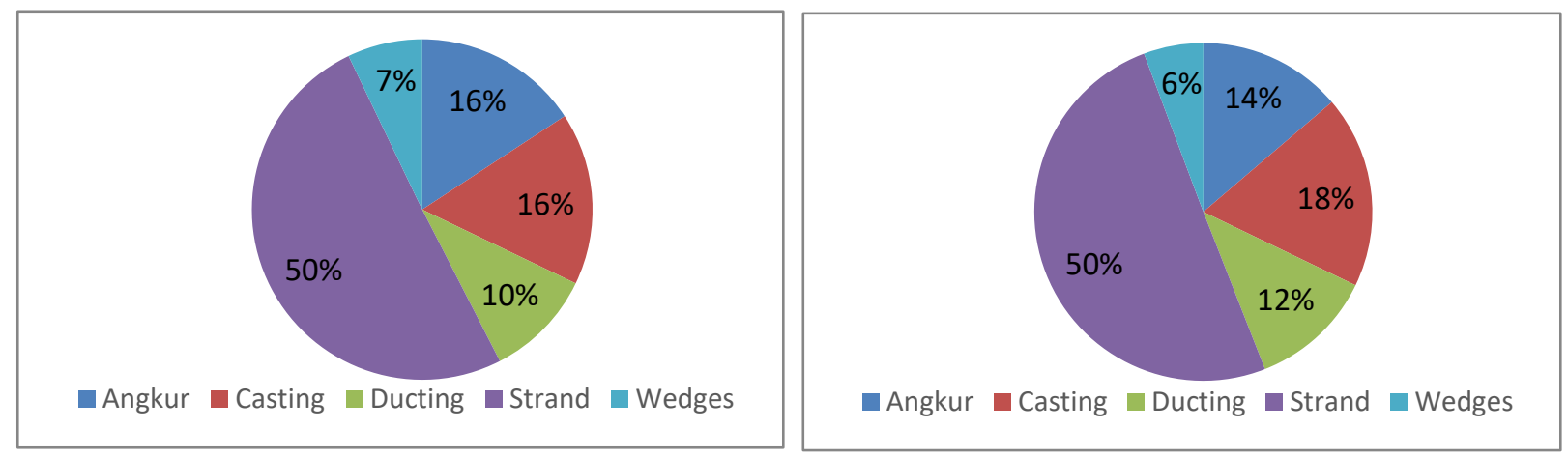

Gambar 5 Grafik komposisi biaya model jembatan bentang $32 \mathrm{~m}$ sistem strand 0,5" dan 0,6"
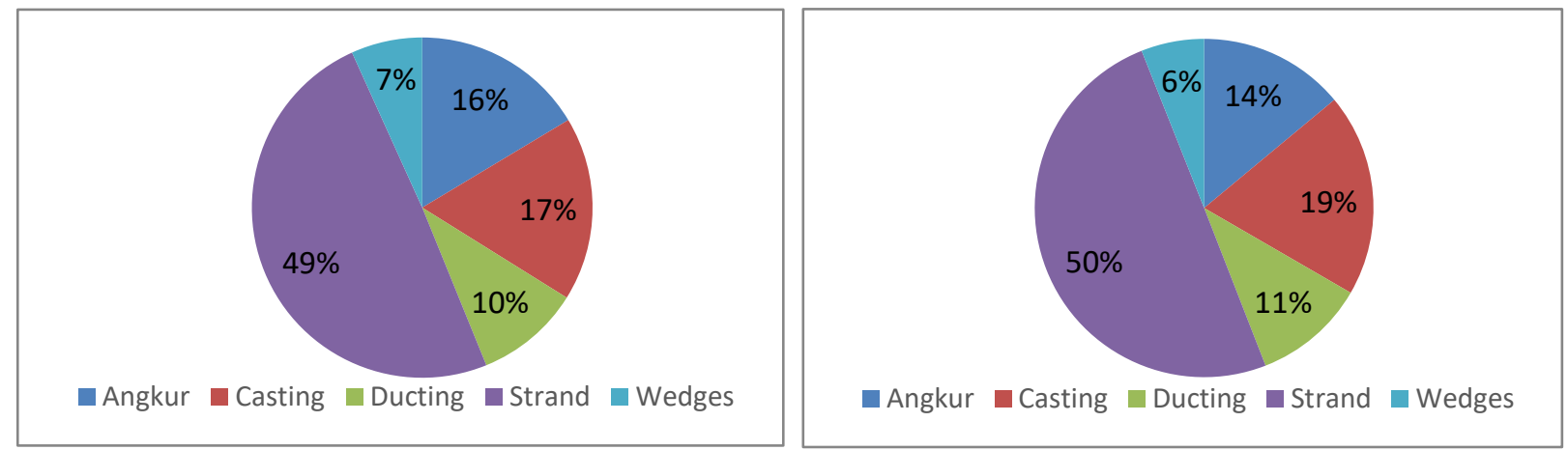

Gambar 6 Grafik komposisi biaya model jembatan bentang $33 \mathrm{~m}$ sistem strand 0,5" dan 0,6" 

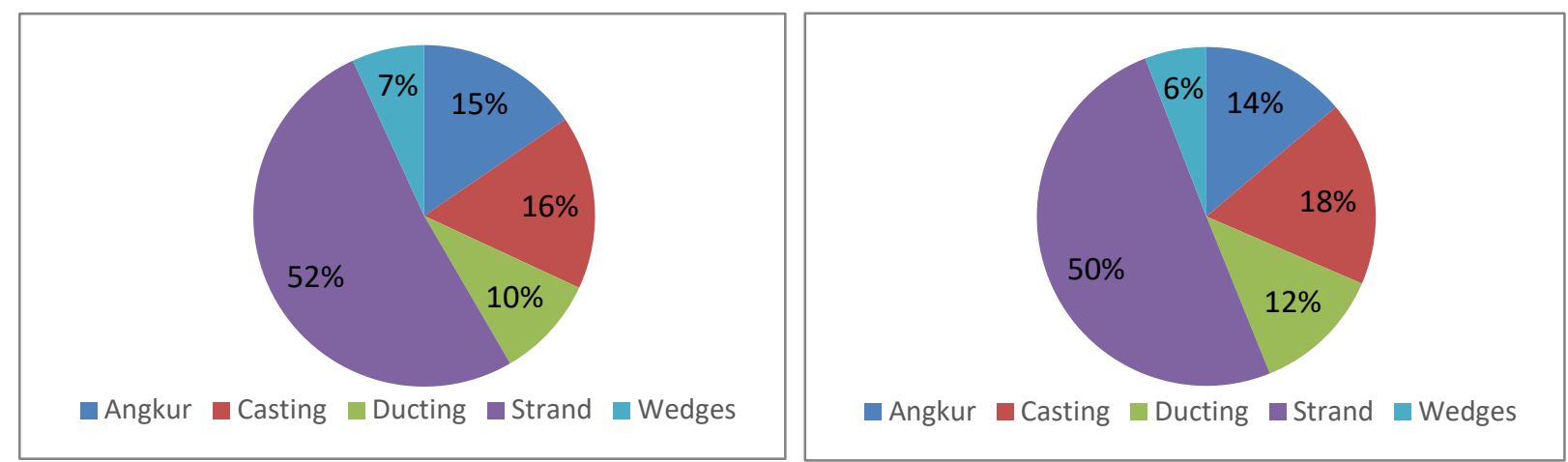

Gambar 7 Grafik komposisi biaya model jembatan bentang $34 \mathrm{~m}$ sistem strand 0,5 " dan 0,6"
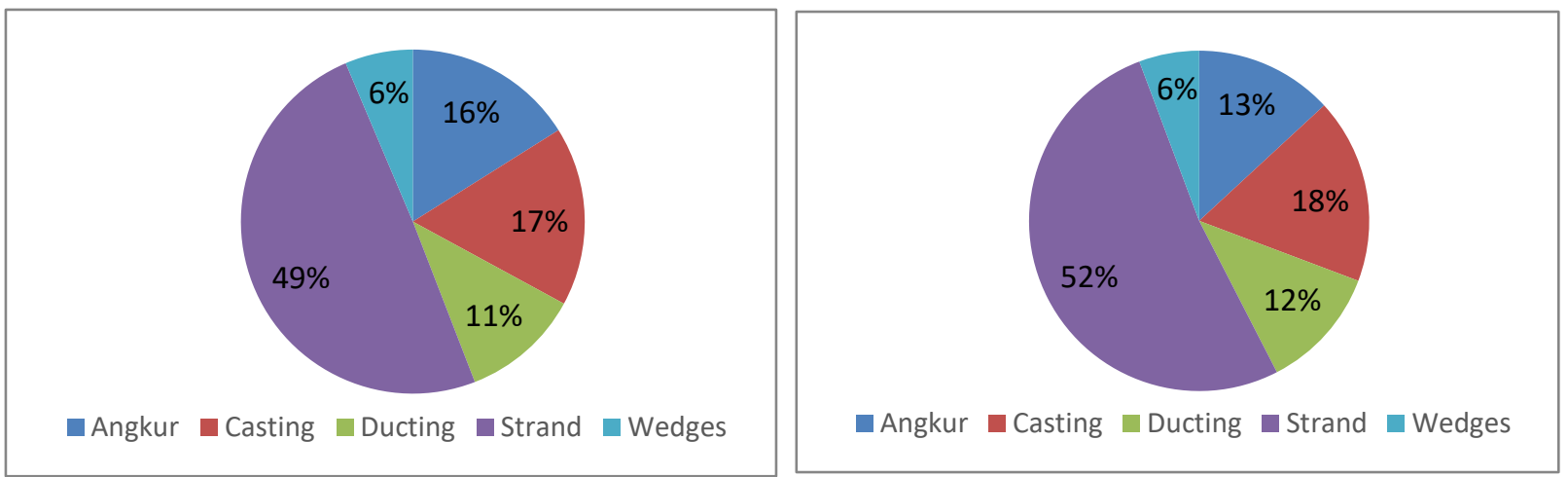

Gambar 8 Grafik komposisi biaya model jembatan bentang $35 \mathrm{~m}$ sistem strand 0,5 ” dan 0,6"

Berdasarkan hasil analisis biaya yang telah dituangkan dalam grafik diatas, dapat terlihat bahwa strand memiliki komposisi biaya sebesar $46 \%-52 \%$ dari total biaya. Casting sebesar $16 \%-20 \%$, angkur sebesar $13 \%-17 \%$, ducting sebesar $10 \%-12 \%$ dan wedges sebesar 6\% - 7\%. Maka, dapat disimpulkan bahwa komponen strand merupakan bahan yang menyumbangkan kontribusi biaya terbesar terhadap perencanaan PC-I Girder sedangkan wedges menyumbangkan kontribusi biaya terkecil terhadap perencanaan PC-I Girder.

\section{Perbandingan komposisi biaya sistem strand 0,6" terhadap 0,5"}

Berikut dapat dilihat perbandingan efisiensi strand berdasarkan biaya yang digunakan untuk setiap model yang dikaji dapat dilihat pada Gambar 9.

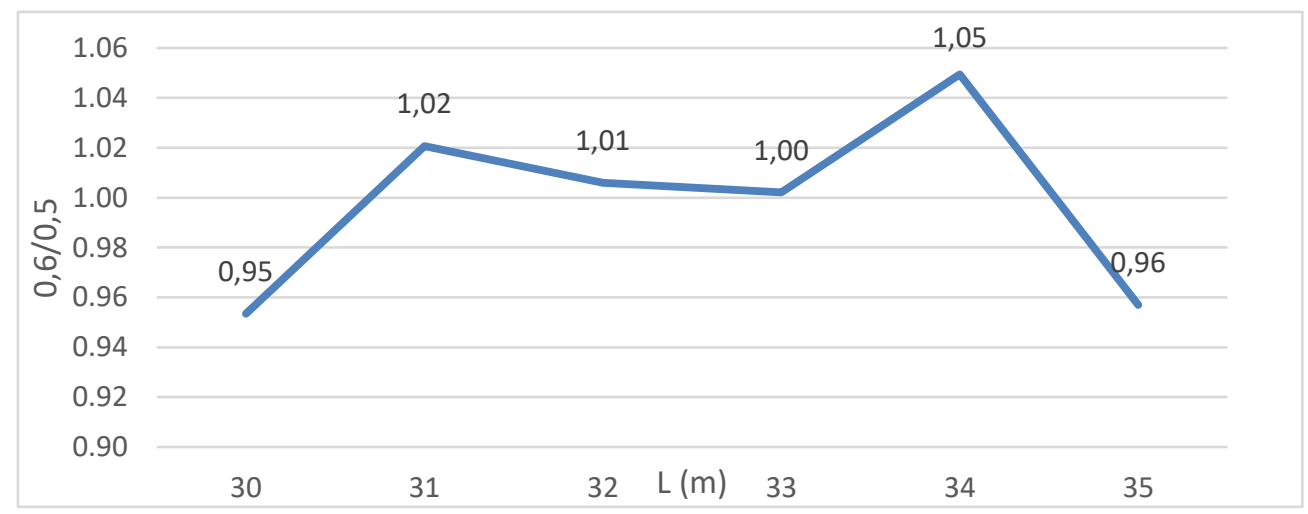

Gambar 9 Grafik perbandingan komposisi biaya sistem strand 0,6" terhadap 0,5"

Dari grafik diatas, didapatkan hasil analisis berupa model jembatan $30 \mathrm{~m}$ memiliki perbandingan komposisi biaya sistem strand 0,6" terhadap 0,5" sebesar 0,95, model jembatan $31 \mathrm{~m}$ sebesar 1,02, model jembatan $32 \mathrm{~m}$ sebesar 1,01, model jembatan $33 \mathrm{~m}$ sebesar 1,00, model jembatan $34 \mathrm{~m}$ sebesar 1,05 dan model jembatan $35 \mathrm{~m}$ sebesar 0,96. Maka, dapat disimpulkan bahwa efisiensi sistem strand 0,5 " dan 0,6 " bersifat fluktuatif bergantung dari 
Kajian Efisiensi Perencanaan PC-I Girder dengan Jessen Richarlim, et.al. Menggunakan Sistem Strand 0,5" dan 0,6" terhadap

Kekuatan dan Biaya

model jembatan yang ditinjau. Tetapi jika dilihat dari Gambar 10, sistem strand 0,5 " memiliki efisiensi biaya yang lebih baik sebanyak 4 model yaitu jembatan yang memiliki bentang $31 \mathrm{~m}, 32 \mathrm{~m}, 33 \mathrm{~m}$ dan $34 \mathrm{~m}$. Sedangkan sistem strand 0,6" memiliki efisiensi biaya yang lebih baik pada 2 model jembatan yang memiliki bentang $30 \mathrm{~m}$ dan $35 \mathrm{~m}$.

\section{KESIMPULAN DAN SARAN}

\section{Kesimpulan}

Dari hasil kajian yang dilakukan, dapat disimpulkan beberapa hal sebagai berikut:

1. Dari hasil perbandingan komposisi biaya dapat dilihat bahwa komponen yang paling berpengaruh pada perencanaan struktur prestress berdasarkan biayanya dari tinggi ke rendah yaitu strand, casting, angkur, ducting dan wedges.

2. Dari hasil perbandingan efisiensi strand 0,5 " dan 0,6 " terhadap setiap model struktur menghasilkan hasil yang fluktuatif. Namun dari grafik komposisi biaya dapat dilihat bahwa kenaikan biaya yang signifikan terjadi karena adanya penambahan tendon. Karena adanya penambahan tendon maka menyebabkan tambahan bahan seperti angkur, casting dan ducting sehingga biaya akan meningkat.

3. Dari hasil perhitungan, desain struktur jembatan bentang $31 \mathrm{~m}, 32 \mathrm{~m}, 33 \mathrm{~m}$ dan $34 \mathrm{~m}$ dengan menggunakan sistem strand 0,5 " lebih efisien dibandingkan dengan sistem strand 0,6" dari segi biaya. Namun pada struktur jembatan bentang $30 \mathrm{~m}$ dan $35 \mathrm{~m}$, sistem strand 0,6 " memiliki efisiensi biaya yang lebih baik dibandingkan sistem strand $0,5 "$.

4. Dari hasil perhitungan dapat disimpulkan bahwa banyaknya strand yang terisi dalam setiap jenis angkur mempengaruhi efisiensi sistem strand. Semakin banyak jumlah strand yang mengisi angkur, maka semakin efisien juga hasil yang didapatkan. Hal ini dapat dilihat pada Grafik 4.24 model jembatan bentang jembatan $30 \mathrm{~m}$. Pada grafik menunjukkan efisiensi sistem strand 0,6" lebih baik dibanding 0,5", hal ini terjadi karena pada sistem strand 0,6 " semua angkur terisi penuh dengan strand sedangkan pada sistem strand 0,5 " terdapat angkur yang tidak terisi penuh dengan strand.

\section{Saran}

Beberapa hal yang dapat dipertimbangkan untuk kajian lebih lanjut antara lain:

1. Pembebanan yang diberikan dapat lebih bervariasi, dapat ditambah seperti beban angin, beban gempa dan beban lainnya sehingga perencanaan dapat lebih mendekati kondisi yang terjadi di lingkungan tertentu.

2. Dapat dilakukan kajian dengan model serupa dengan kondisi struktur statis tak tentu.

3. Komposisi biaya dapat lebih diperluas dengan melihat aspek pelaksanaan, penggunaan alat, waktu yang diperlukan, kondisi lingkungan, keterampilan pekerja dan aspek lainnya yang mempengaruhi biaya perencanaan.

4. Dapat dilakukan kajian dengan model serupa dengan metode stressing pre-tension sehingga dapat dilihat perbandingannya.

5. Balok PC-I girder dapat diperbesar agar web girder semakin lebar sehingga analisis sistem strand dengan konfigurasi jumlah strand yang digunakan dapat lebih luas.

\section{DAFTAR PUSTAKA}

Lin, T. Y and Burns, Ned. H. Desain Struktur Beton Prategang. $3^{\text {rd }}$ ed, BinarupaAksara, 2000.

Manu, Agus Iqbal. Dasar-Dasar Perencanaan Jembatan Beton Bertulang. $1^{\text {st }}$ ed, DPU, Mediatama Sapyakarya, 1995.

Nawy, Edward G., and H. Wibi. Hardani. Beton Prategang: Suatu Pendekatan Mendasar, 1 ${ }^{\text {st }}$ ed, Erlangga, 2001. Raju, N. Khrisna. Beton Prategang. $2^{\text {nd }}$ ed, Erlangga, 2001. 